\title{
ILEO COLO-COLIC INTUSSUSCEPTION: A RARE CASE REPORT
}

Keisham Lokendra Singh1, Goutam Chakravorty², T. Shyamananda Singh ${ }^{3}$, C. H. Arunkumar Singh", G. S. Moirangthem ${ }^{5}$

\section{HOW TO CITE THIS ARTICLE:}

Keisham Lokendra Singh, Goutam Chakravorty, T. Shyamananda Singh, C. H. Arunkumar Singh, G. S. Moirangthem. "Ileo Colo-Colic Intussusception : A Rare Case Report". Journal of Evolution of Medical and Dental Sciences 2014; Vol. 3, Issue 29, July 21; Page: 8214-8217,

DOI: $10.14260 /$ jemds/2014/3033

ABSTRACT: Intussusception is a condition where a segment of intestine invaginates into the adjoining intestinal lumen, causing intestinal obstruction. Mortality rate is less than $1 \%$ if early diagnosis is made and prompt treatment is given. It is very common in children all over the world, especially those under 2 years. The majority of cases occur in the region of the ileocecal valve, and no lead point can be precisely identified. Rarer types are ileoileal, ileocolocolic, colocolic, and ileoileocolic. Almost all cases of colocolic intussusception occur with a lead-point such as polyp or tumoral mass. Here, we present a case of ileocolocolic intussusceptions without a lead point.

KEYWORDS: Intussusception; Ileocolocolic; Children; Intestinal obstruction.

CASE REPORT: A four month old female baby came to the emergency department of our hospital with distension of abdomen and obstipation for 2 days. She was treated in a local health centre following which the symptoms worsened with increased abdominal distension and passing of red mucoid stool.

On examination, she was febrile, toxic looking and severely dehydrated. Pulse rate was $120 / \mathrm{min}$, respiratory rate $34 / \mathrm{min}$ and temperature $38.4^{\circ} \mathrm{C}$. Upper part of the abdomen was distended and bowels sounds were increased. Palpation revealed a firm lump, $5 \times 5 \mathrm{~cm}$ in the right hypochondrium and an empty right iliac fossa. Abdominal x-ray showed multiple air-fluid levels and a gasless lower abdomen. Abdominal ultrasound revealed bowel wall thickening and kidney sign in the hepatic flexure (Fig. 1).

Midline laparotomy was performed. Intraoperative findings included dilated small bowel loops (Fig. 2) and ileocolocolic intussusception (ileum, ascending and transverse colons) without a lead point (Fig. 3).

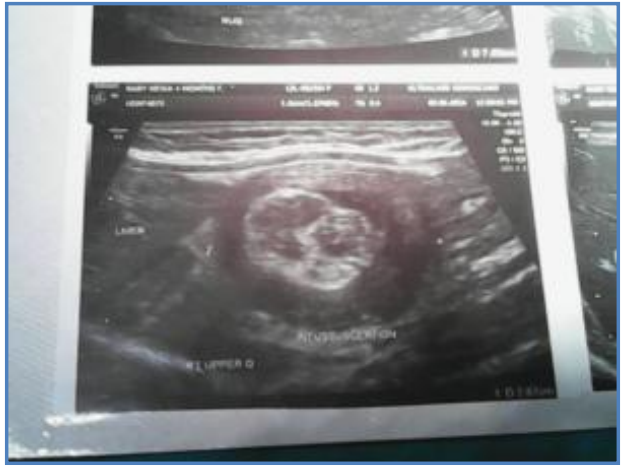

Fig. 1 


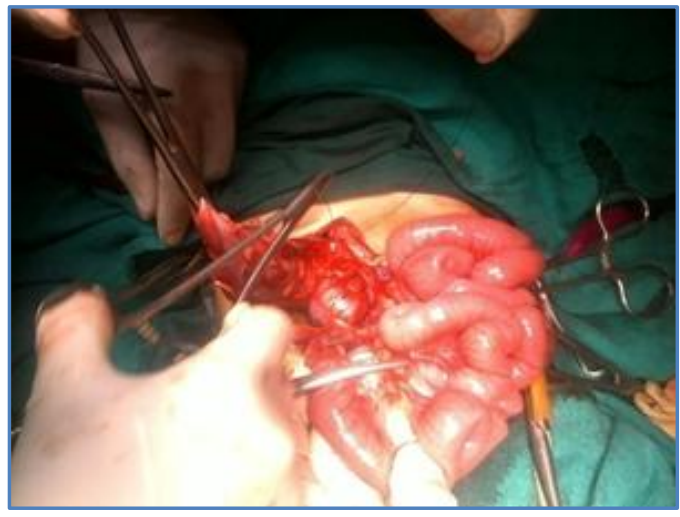

Fig. 2

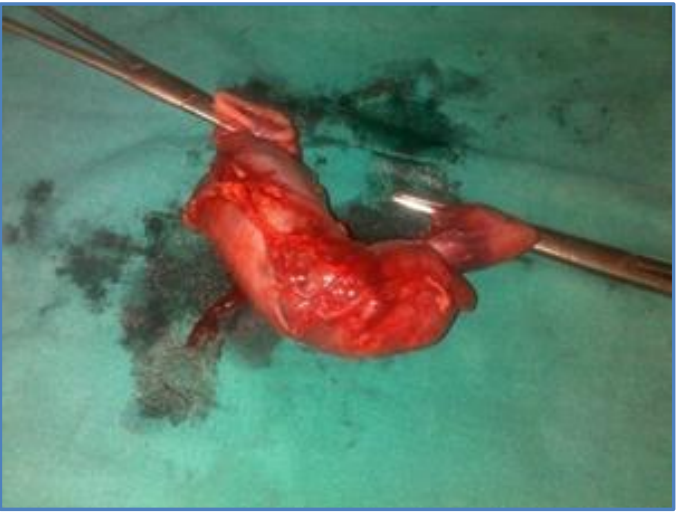

Fig. 3

Segmental resection with ileodescending anastomosis was performed. Post-operative period was uneventful except for a bout of bilious vomiting of around $200 \mathrm{ml}$ on the $1^{\text {st }}$ post-operative day. Enteral feeding was started on the $5^{\text {th }}$ post-operative day and patient was discharged on $8^{\text {th }}$ postoperative day. Barium enema performed after 2 months was normal and on follow up after 3 months, she was doing fine.

DISCUSSION: Intussusception is the most common cause of acute intestinal obstruction in infants and young children. ${ }^{1}$ But, ileocolocolic intussusception in an infant without a lead point is very rare. Eighty percent of patients are younger than 24 months $^{2}$ and $95 \%$ of cases are ileocolic in location, with an equal percentage in which no pathologic lead point is evident on barium enema or laparotomy. ${ }^{3}$

Other types of intussusception that are rarer and have an anatomic lead point occur in children older than 2 years of age. ${ }^{4}$ Almost all cases of colocolic intussusception occur with a leadpoint such as polyp or tumoral mass, a review of English written literature showed only three cases without a lead- point. .-7 $^{-1}$

A variety of pathologic conditions associated with intussusception, including small bowel lymphoma, Meckel diverticulum, duplication cysts, polyps, vascular malformations, inverted appendiceal stumps, parasites (eg, Ascaris lumbricoides), Henoch-Schönlein purpura, and cystic fibrosis, have been described.

Pediatric patients presenting with documented colocolic intussusception should suggest the possibility of a colonic polyp or other mass lesion. Careful physical examination and barium studies should provide important diagnostic clues. ${ }^{8}$ In our case, pathological lead point was not found at both laparotomy and barium enema after two months of follow up. She did not have any gastrointestinal complaints at the time of follow up three months after surgery.

Patients with intussusception typically develop the sudden onset of intermittent, severe, crampy, progressive abdominal pain, accompanied by inconsolable crying and drawing up of the legs toward the abdomen. Classic triad of intussusception including crampy abdominal pain, vomiting and bloody stool are seen in only $21 \%$ of patients and $70 \%$ of cases present with only two signs. ${ }^{4}$

Imaging studies done in the diagnosis of intussusception include radiography, ultrasonography, computed tomography and contrast enema. 
Intussusception can complicate specific inflammatory disease of the intestine. Occurring of it in the course of a Salmonella typhi is reported. ${ }^{9}$ But careful examination of all regions of the intestine during laparotomy for detection of an underlying pathologic lead point such as enteritis or significant inflammation was ruled out and the probability of enteritis as a lead point was eliminated in this patient.

CONCLUSION: A 5 months old female baby having ileocolocolic intussusception without a lead point has been reported. Such lesion is reportedly very rare and only three cases have reported in the literature so far. In infants and children especially with dysentery, colicky pain abdomen, abdominal distension and no response to antibiotic, intussusception should be suspected early and abdominal ultrasound should be performed to confirm the diagnosis.

\section{REFERENCES:}

1. Bines JE, Ivanoff $\mathrm{B}$, Justice $\mathrm{F}$, et al. Clinical case definition for the diagnosis of acute intussusception. J Pediatr Gastroenterol Nutrition. 2004; 39 (5): 511-8.

2. Wyllie R. Intussusception. In: Behrman RE, Kliegman RM, Jenson HB (eds). Nelson Textbook of Pediatrics. 17th ed. Philadelphia; Saunders. 2004; Pp: 1242-3.

3. AL, Garvey R, Vaness DG. Colocolic intussusception in a three-year-old child caused by a colonic polyp. Connecticut Med. 1990: 54 (9): 492-4.

4. Young LL. Intussusception. In: Yamamoto LG, Inaba AS, Okamoto JK, et al (eds). Case Based Pediatrics for Medical Students and Residents. Online Pediatrics Textbook. 2004. Available at: www.hawaii.edu/medicine/pediatrics/pedtext/ Access date: Dec 2004.

5. Bohrer SP. Colonic mass; an unusual adult case of colocolic intussusception in which no tumor could be identified. JAMA. 1963, 185:206-7.

6. Devin R. Case of acute colocolic invagination in an adult without intestinal tumor. Marseille chirurgical. 1955; 7 (1): 87.

7. Saidi F. Colocolic intussusception in adults due to invagination of the cecal wall. Amer J Surg. 1966; 112 (6): 927-31.

8. Arthur AL, Garvey R, Vaness DG. Colocolic intussusception in a three-year-old child caused by a colonic polyp. Connecticut Med. 1990:54(9):492-4.

9. Goodall P. Intussusception in adults complicating specific inflammatory disease of intestine. Gut. 1963; 4 (2): 132-5. 


\section{CASE REPORT}

\section{AUTHORS:}

1. Keisham Lokendra Singh

2. Goutam Chakravorty

3. T. Shyamananda Singh

4. C. H. Arunkumar Singh

5. G. S. Moirangthem

\section{PARTICULARS OF CONTRIBUTORS:}

1. Registrar, Department of Surgery, Regional Institute of Medical Sciences, Imphal, Manipur.

2. Junior Resident, Department of Surgery, Regional Institute of Medical Sciences, Imphal, Manipur.

3. Junior Resident, Department of Surgery, Regional Institute of Medical Sciences, Imphal, Manipur.
4. Professor, Department of Surgery, Regional Institute of Medical Sciences, Imphal, Manipur.

5. Professor and HOD, Department of Surgery, GI \& MAS Unit.

\section{NAME ADDRESS EMAIL ID OF THE CORRESPONDING AUTHOR:}

Dr. Keisham Lokendra Singh, Sagolband Tera,

Khuraijam Leikai, Imphal-795001, Manipur.

Email: drkeisham@hotmail.com

Date of Submission: 07/07/2014. Date of Peer Review: 08/07/2014. Date of Acceptance: 14/07/2014. Date of Publishing: 19/07/2014. 